\title{
Sulfate removal from aqueous solutions using esterified wool fibers: isotherms, kinetic and thermodynamic studies
}

\author{
Fatine Akoh, ${ }^{\mathrm{a}, \mathrm{b}}$, Hayat Bouchoum ${ }^{\mathrm{a}, \mathrm{b}}$, Mehdi El Bouchti ${ }^{\mathrm{b}}$, Omar Cherkaoui $^{\mathrm{b}}$, Amane Jada $^{\mathrm{c}, \mathrm{d}, *}$, \\ Mohamed Tahiria \\ ${ }^{a}$ Geosciences Laboratory, Faculty of Sciences Ain Chock, Hassan II University, B.P 5366 Maarif 20100, Casablanca, Morocco, \\ emails:akoh.fatine@gmail.com (F. Akoh),bouchoum.hayat@gmail.com (H. Bouchoum),mohtahiri@yahoo.fr (M. Tahiri) \\ ${ }^{b}$ REMTEX Laboratory, Higher School of Textile and Clothing Industries, Casablanca, Morocco, \\ emails: elbouchti@esith.ac.ma (M. El Bouchti),cherkaoui@esith.ac.ma (O.Cherkaoui) \\ 'University Haute Alsace, CNRS, IS2M, UMR7361, F-68100 Mulhouse, France, email: amane.jada@uha.fr (A. Jada) \\ ${ }^{d}$ University Strasbourg, Strasbourg, France
}

Received 14 August 2019; Accepted 17 January 2020

\section{A B S T R A C T}

This work deals with the removal of sulfate ions from aqueous solutions onto modified wool fibers (WFs) used as adsorbent. The esterified wool fibers (EWFs) were prepared from the esterification of the pristine raw wool fibers (RWFs) by using methanol in the presence of $\mathrm{HCl}$ as a catalyst. Thereafter, we characterized the modified wool fibers by using various methods, such as titration for functionalization degree calculation, Fourier transform infrared spectroscopy and thermogravimetric analysis. Further, we studied parameters affecting sulfate removal from water onto both the EWFs and the RWFs, such as solution initial pH, initial concentrations, contact time, a mass of the adsorbent and the temperature. To assess the adsorption theoretical trends of sulfate ions from water onto the EWFs adsorbent, we compared the experimental adsorption results to Langmuir, Freundlich, and Dubinin-Radushkevich models. A good agreement was found between the experimental data and those predicted by the Langmuir model, which yielded a maximum monolayer adsorption capacity of $123.08 \mathrm{mg} \mathrm{g}^{-1}$. Also, the adsorption kinetic results of the sulfate ions removal from water onto the EWFs adsorbent were found to follow a pseudo-second-order model. Finally, adsorption thermodynamic parameters including Gibbs free energy $\Delta G^{\circ}$, enthalpy $\Delta H^{\circ}$, and entropy $\Delta S^{\circ}$, have been estimated and showed that the sulfate ions adsorption onto the EWFs adsorbent is spontaneous, endothermic and favorable. The overall data indicate that the EWFs have economic and environmental advantages, since their uses are not limited only to adsorption but they can also be regenerated.

Keywords: Esterification; Methanol; Adsorption; Water; Regeneration

\footnotetext{
* Corresponding author.

Presented at the 7th International Conference on Sustainable Solid Waste Management, $26-29$ June 2019, Heraklion, Crete Island, Greece 1944-3994/1944-3986 @ 2020 Desalination Publications. All rights reserved.
} 